\title{
Spotlight on pembrolizumab in non-small cell lung cancer: the evidence to date
}

This article was published in the following Dove Press journal:

OncoTargets and Therapy

23 September 2016

Number of times this article has been viewed

\section{Pankit Vachhani \\ Hongbin Chen}

Department of Medicine, Roswell Park Cancer Institute, Buffalo, NY, USA
Correspondence: Hongbin Chen

Department of Medicine, Roswell Park

Cancer Institute, Elm and Carlton Streets,

Buffalo, NY 14263, USA

Tel + I 7168453099

Fax + I 7168458935

Email hongbin.chen@roswellpark.org

\begin{abstract}
Immunotherapy with immune checkpoint inhibitors has opened a new arena in cancer therapeutics. Pembrolizumab is a highly selective anti-programmed cell death protein 1 (PD-1) antibody that has shown efficacy, leading to survival benefit and durable responses, in some patients with non-small cell lung cancer (NSCLC). It has been approved by the US Food and Drug Administration for the treatment of patients with metastatic NSCLC, whose tumors express PD-1 ligand 1 (PD-L1), with disease progression on or after platinum-containing chemotherapy. Here, we briefly discuss the PD-1/PD-L1 pathway and pembrolizumab before delving into the clinical trials that have led to its just-mentioned approval in NSCLC and ongoing clinical trials. Finally, we discuss the use of biomarkers, primarily PD-L1, in the context of pembrolizumab and NSCLC.
\end{abstract}

Keywords: pembrolizumab, KEYNOTE, non-small cell lung cancer

\section{Introduction}

Lung cancer incidence rates started declining in the US from mid-1980s for men and from late-1990s for women. ${ }^{1}$ Nevertheless, it continues to be the leading cause of cancer death for both men and women. In fact, $27 \%$ of all cancer deaths are attributable to lung cancer. Non-small cell lung cancer (NSCLC), an umbrella term that encompasses pathologically distinct subtypes including adenocarcinoma, squamous cell carcinoma, large-cell carcinoma, and more poorly differentiated variants, constitutes $85 \%$ of all lung cancers with the adenocarcinoma subtype $>50 \%$ of all lung cancers. ${ }^{2,3}$

Platinum-based doublet chemotherapies have proved among the most efficacious of chemotherapeutic combinations. ${ }^{4,5}$ However, various other combinations of cytotoxic chemotherapies have not led to better outcomes. ${ }^{4}$ In selective cases, though, certain molecularly targeted therapies have led to superior outcomes compared to standard chemotherapy in NSCLC. ${ }^{3,5}$ Gefitinib, erlotinib, or afatinib is recommended as firstline therapy for patients with sensitive mutation in epidermal growth factor receptor (EGFR) ${ }^{6,7}$ Similarly, crizotinib is recommended as first-line treatment for patients who harbor anaplastic lymphoma kinase $(A L K)$ gene rearrangement, and it can additionally be considered in first line or later treatment of patients with activated ROS1 protooncogene receptor tyrosine kinase (ROS1, activated by chromosomal rearrangement of a portion of ROS1 with one of 12 different partner proteins). ${ }^{6,7}$ These targeted therapies have led to superior outcomes including survival benefits as compared to standard chemotherapy. ${ }^{8-11}$ Bevacizumab, an antiangiogenic agent, has also shown benefit in certain patient populations. ${ }^{12}$

Despite these targeted therapies, prolonged disease control and long-term survival outcomes continue to evade. ${ }^{5,7}$ Furthermore, only a small fraction of NSCLC patients 
have EGFR mutation (10\%-15\% in Western populations) or ALK rearrangement $(2 \%-7 \%){ }^{13,14}$ Primary or acquired mutations also lead to drug resistance and hence thwart the efficacy. ${ }^{15-17}$

In this context, immune-based therapies have provided a new facet to the management of NSCLC. At best, the early immune-based therapies including first-generation vaccines, interleukin-2, and interferon had limited efficacy potentially because these were not target specific and had significant toxicities. ${ }^{18-21}$ However, the newer immunotherapeutic approaches including vaccine development and immune checkpoint inhibition have generated significant interest. ${ }^{5}$ Immune checkpoints refer to a variety of inhibitory pathways that are crucial for maintaining self-tolerance and modulating the duration and amplitude of physiological immune responses in peripheral tissues in order to minimize collateral tissue damage. ${ }^{22}$ Tumor cells co-opt these pathways in order to escape immune destruction. ${ }^{22,23}$ The blockade on such immune checkpoints can effectively release the brakes on immune system, thus leading to antigen-specific T-cell responses. While many such immune checkpoints exist, two distinct pathways regulated by cytotoxic T-lymphocyteassociated antigen 4 (CTLA4) and programmed cell death protein 1 (PD-1) and its ligand PD-L1 have truly come to clinical forefront. ${ }^{22,24}$

\section{PD-I/PD-LI pathway in oncology}

PD- 1 is a type 1 transmembrane protein of the Ig superfamily that engages in inhibitory signal transmission. ${ }^{25,26}$ Compared to CTLA-4, PD-1 is expressed more broadly and includes tumor-infiltrating lymphocytes (TIL; mainly CD4+ T-cells of which a large proportion are regulatory T-cells [T-regs]), B-cells, natural killer cells, monocytes, dendritic cells, and host tissues. ${ }^{22,27,28}$

PD-1 has two known ligands - PD-1 ligand 1 (PD-L1; also known as B7-H1 and CD274) and PD-1 ligand 2 (PD-L2; also known as B7-DC and CD273). ${ }^{22}$ PD-L1, the primary ligand, is expressed by various tumors, including lung cancer, through either innate or adaptive immune resistance mechanisms..$^{27,29,30}$ Upon binding to one of its ligands, PD-1 inhibits kinases that are involved in T-cell activation through the inhibitory phosphatase SHP2. ${ }^{31,32}$ The interaction inhibits the proliferation, survival, and effector function of $\mathrm{CD}^{+}$cytotoxic T-lymphocyte (CTL), thus inducing apoptosis of TIL. ${ }^{33}$ Since the interaction also inhibits the T-cell receptor-mediated effector functions and increases $\mathrm{T}$-cell migration within tissues, this pathway can modify the duration of the T-cell antigen-presenting cell or T-cell target cell contact. ${ }^{23,34}$ Further, many tumors are highly infiltrated with T-regs that suppress effector immune responses in the tumor microenvironment, and PD-1, which is highly expressed on T-regs, can increase proliferation of T-regs in the presence of PD-L1. Collectively, the PD-1/PD-L1 interaction can lead to a variety of effects, and its blockade can lead to enhancement of intratumoral immune responses.

With the just-mentioned biological underpinnings, numerous preclinical data, and on the back of anti-CTLA-4 antibody success, multiple anti-PD-1 and anti-PD-L1 antibodies have been launched in clinical trials. Of these, nivolumab (OPDIVO; Bristol-Myers Squibb, New York, NY, USA) and pembrolizumab (KEYTRUDA; Merck \& Co., Inc., Whitehouse Station, NJ, USA) have achieved US Food and Drug Administration (FDA) approval in NSCLC. Both are also FDA approved in melanoma with the former approved for renal cell cancer and Hodgkin lymphoma as well. In this review, we focus on pembrolizumab in NSCLC.

\section{Pembrolizumab}

Pembrolizumab, previously known as lambrolizumab and MK-3475, was constructed by grafting the variable region sequences of a very-high-affinity mouse antihuman PD-1 antibody into a human IgG4 immunoglobulin with a stabilizing S228P Fc alteration. ${ }^{35}$ As such, it is a potent, fully humanized, highly selective, 149 kDa IgG4 kappa monoclonal antibody against PD-1. ${ }^{36-38}$ Since the IgG4 immunoglobulin subtype does not engage Fc receptors or activates complement, cytotoxic effects of the antibody, when it binds to the T-cells that it is intended to activate, are avoided. ${ }^{35}$ Pharmacokinetic analysis has shown that no dose adjustment is needed in patients with renal impairment or those with mild hepatic impairment. ${ }^{36}$ Steady-state concentrations were reached by 19 weeks of repeated dosing with every 3 -week regimen. Clearance, steady-state volume of distribution, and terminal half-life were $202 \mathrm{~mL} / \mathrm{d}, 7.38 \mathrm{~L}$, and 27 days, respectively. Given that IgG4 antibodies can cross placenta and because the PD-1/PD-L1 signaling pathway is important in the induction of maternal immune tolerance to fetal tissue in animal models, besides the lack of studies in pregnant human subjects, it bears FDA pregnancy category D rating. ${ }^{36}$ In NSCLC, pembrolizumab was approved by the US FDA on October 2, 2015, for patients with metastatic disease, whose tumors express PD-L1 as determined by an FDA-approved test, with disease progression on or after platinum-containing chemotherapy. For those patients with EGFR mutation or ALK rearrangement, it is approved in the setting of disease progression on FDA-approved therapy for these aberrations. 
The clinical trials leading to the approval and other relevant clinical trials are described further (Table 1).

\section{KEYNOTE-00 I trial}

KEYNOTE-001 is a large, multicohort, international, Phase I trial that was designed to study pembrolizumab in patients with advanced solid tumors - primarily melanoma and NSCLC. ${ }^{39,40}$

The first-in-human dose-finding cohort evaluated the safety, pharmacokinetics, and pharmacodynamics of pembrolizumab in patients with advanced solid tumors (cohort A). ${ }^{39}$

Further, it aimed to study the antitumor activity and identify the maximum tolerated dose of pembrolizumab. Dose escalation was conducted in the traditional 3+3 design in this initial, open-label study that enrolled patients between April 27, 2011, and August 1, 2012. Seventeen patients received pembrolizumab $1 \mathrm{mg} / \mathrm{kg}, 3 \mathrm{mg} / \mathrm{kg}$, or $10 \mathrm{mg} / \mathrm{kg}$ intravenously every 2 weeks until progression or intolerable toxicity, while 13 patients participated in a 3-week intrapatient dose escalation (dose range, $0.005-10 \mathrm{mg} / \mathrm{kg}$ ) followed by $2 \mathrm{mg} / \mathrm{kg}$ or $10 \mathrm{mg} / \mathrm{kg}$ every 3 weeks. In all, eight patients had NSCLC. No dose-limiting toxicities were observed, and no maximum tolerated dose was reached. However, per protocol, the maximum administered dose was $10 \mathrm{mg} / \mathrm{kg}$ every 2 weeks. Treatment-related adverse events (AEs) occurred in 21 patients $(70 \%)$. There were no grade 3 or 4 treatmentrelated AEs. Immune-related AEs (irAEs) occurred in five patients $(17 \%)$. Antitumor activity was observed at all doses and schedules; two patients experienced complete responses, two patients had partial responses, while 15 patients with various malignancies experienced stable disease. The investigators concluded that pembrolizumab was well tolerated and associated with durable antitumor activity in multiple solid tumors, with $2 \mathrm{mg} / \mathrm{kg}$ every 3 weeks being the lowest dose holding full potential for antitumor activity.

Based on this first-in-human experience, the investigators expanded KEYNOTE-001 to further evaluate the side effects, safety, and antitumor activity of pembrolizumab in patients with advanced NSCLC (cohorts C and F). ${ }^{40}$

They additionally sought to define and validate tumor PD-L1 expression level that was associated with a higher likelihood of clinical benefit from pembrolizumab. From May 2012 to February 2014, 495 patients, out of a total of 1,143 patients screened, were enrolled. These patients had locally advanced or metastatic NSCLC, Eastern Cooperative Oncology Group (ECOG) performance status of 0 or 1 , and they were 18 years or older. Key exclusion criteria included history of pneumonitis, systemic immunosuppressive therapy, or active autoimmune disease. Patients received pembrolizumab intravenously at a dose of $2 \mathrm{mg} / \mathrm{kg}$ every 3 weeks $(\mathrm{n}=6)$ or $10 \mathrm{mg} / \mathrm{kg}$ every 3 weeks $(\mathrm{n}=202)$ or $10 \mathrm{mg} / \mathrm{kg}$ every 2 weeks $(n=287)$ over a 30 -minute period. This same set of 495 patients was simultaneously also divided into two groups - training group $(n=182)$ and validation group $(n=313)-$ in order to study the association between PD-L1 expression and pembrolizumab efficacy. To this end, a prototype immunohistochemical assay was used to determine PD-L1 status for eligibility (membranous staining of at least $1 \%$ of neoplastic and intercalated mononuclear inflammatory cells within tumor nests or a distinctive banding pattern of mononuclear inflammatory cells in the stroma adjacent to tumor nests). A clinical trial assay developed by Dako Corp. (Carpinteria, CA, USA) that used the anti-PD-L1 22C3 murine monoclonal antibody (Merck \& Co., Inc.) was used to determine PD-L1 expression level with results being reported as percentage of neoplastic cells that showed membranous staining of PD-L1 (proportion score). Pembrolizumab was given until unacceptable toxicity, disease progression based on investigator-assessed immune-related response criteria, or patient/investigator decision. Primary radiographic assessment was done using Response Evaluation Criteria in Solid Tumors (RECIST) Version 1.1, while immune-related response criteria were also used for evaluation.

The median duration of follow-up was 10.9 months (range: 5.2-27.5 months), and 115 patients (23.2\%) continued to receive treatment at the time of data cutoff for analysis (August 29, 2014). Analyzing all groups in whole, overall response rate (ORR) was 19.4\% (95\% confidence interval [95\% CI]: 16.0-23.2); ORR for previously treated patients was $18.0 \%(\mathrm{n}=394,95 \% \mathrm{CI}$ : $14.4-22.2)$ and that for previously untreated patients was $24.8 \%(n=101,95 \%$ CI: 16.7-34.3). Importantly, the ORR was similar regardless of the dose, schedule, or histopathology. Median progressionfree survival (PFS) for all patients was 3.7 months (95\% CI: 2.9-4.1), for previously treated patients was 3.0 months $(95 \%$ CI: 2.2-4.0), and for treatment-naïve patients was 6.0 months (95\% CI: 4.1-8.6). Similarly, the median overall survival (OS) for all patients was 12.0 months (95\% CI: 9.3-14.7), for previously treated patients was 9.3 months $(95 \% \mathrm{CI}$ : 8.4-12.4), and for treatment-naïve patients was 16.2 months (95\% CI: 16.2 to not reached at the time of analysis).

As for the biomarker analysis, the investigators adjudged membranous PD-L1 expression in at least $50 \%$ of tumor cells as the cutoff based on several methods of pathological assessment in the training group. When applied to the validation group, the 
Table I Clinical trials of pembrolizumab in NSCLC

\begin{tabular}{|c|c|c|c|c|c|c|c|}
\hline Trial & Phase & Line of therapy & $\mathbf{N}$ & Disease setting & Characteristics & PD-LI positivity & Treatment arms \\
\hline $\begin{array}{l}\text { KEYNOTE-00 I39,40 } \\
\text { (NCTOI 295827) }\end{array}$ & I & $\begin{array}{l}\text { Second line and } \\
\text { beyond }\end{array}$ & 495 & $\begin{array}{l}\text { Advanced; } \\
\text { treated and } \\
\text { untreated }\end{array}$ & $\begin{array}{l}\text { Six-part, open-label, } \\
\text { randomized }\end{array}$ & $\begin{array}{l}<1 \% \text { versus } \\
1 \%-49 \% \text { versus } \\
\geq 50 \%\end{array}$ & $\begin{array}{l}\text { Pembrolizumab } 2 \mathrm{mg} / \mathrm{kg} \\
\text { q3 weeks versus } 10 \mathrm{mg} / \mathrm{kg} \\
\text { q3 weeks versus } 10 \mathrm{mg} / \mathrm{kg} \\
\text { q2 weeks }\end{array}$ \\
\hline $\begin{array}{l}\text { KEYNOTE-0104I } \\
\text { (NCTOI905657) }\end{array}$ & II/III & $\begin{array}{l}\text { Second line (after } \\
\text { platinum-containing } \\
\text { doublet) }\end{array}$ & $\mathrm{I}, 034$ & $\begin{array}{l}\text { Advanced; } \\
\text { second-line and } \\
\text { above }\end{array}$ & $\begin{array}{l}\text { Three arms, open- } \\
\text { label, randomized }\end{array}$ & $\begin{array}{l}I \%-49 \% \text { versus } \\
\geq 50 \%\end{array}$ & $\begin{array}{l}\text { Pembrolizumab } 2 \mathrm{mg} / \mathrm{kg} \\
\text { versus pembrolizumab } \\
10 \mathrm{mg} / \mathrm{kg} \text { versus docetaxel } \\
75 \mathrm{mg} / \mathrm{m}^{2} \mathrm{q} 3 \text { weeks }\end{array}$ \\
\hline
\end{tabular}

\begin{tabular}{|c|c|c|c|c|c|c|c|}
\hline $\begin{array}{l}\text { KEYNOTE-0II } \\
\text { (NCTOI840579) }\end{array}$ & I & Second line & 30 & Advanced & $\begin{array}{l}\text { Two-part, open-label, } \\
\text { nonrandomized }\end{array}$ & Not defined & $\begin{array}{l}\text { Part A: pembrolizumab } \\
\text { ( } 2 \mathrm{mg} / \mathrm{kg} \text { vs } 10 \mathrm{mg} / \mathrm{kg} \text { arms); } \\
\text { Part B: pembrolizumab + } \\
\text { platinum doublet }\end{array}$ \\
\hline $\begin{array}{l}\text { KEYNOTE-02 I }{ }^{42-45} \\
\text { (NCT02039674) }\end{array}$ & $\mathrm{I} / \mathrm{II}$ & First line & 308 & $\begin{array}{l}\text { Advanced or } \\
\text { metastatic }\end{array}$ & $\begin{array}{l}\text { Eight cohorts, open- } \\
\text { label, randomized }\end{array}$ & Any & Eight different arms \\
\hline
\end{tabular}

$\begin{array}{llll}\begin{array}{l}\text { KEYNOTE-025 } \\ \text { (NCT02007070) }\end{array} & \begin{array}{l}\text { Second line (after } 24 \\ \text { platinum-containing } \\ \text { doublet) }\end{array} & \begin{array}{l}\text { PD-LI-positive } \\ \text { advanced }\end{array} & \begin{array}{l}\text { Single cohort, open- Positive } \\ \text { label, nonrandomized }\end{array}\end{array}$

\begin{tabular}{|c|c|c|c|c|c|c|c|}
\hline $\begin{array}{l}\text { MK-3475 in melanoma I } \\
\text { and NSCLC patients } \\
\text { with brain metastases } \\
\text { (NCT02085070) }\end{array}$ & II & First line & 64 & $\begin{array}{l}\text { Untreated brain } \\
\text { metastasis }\end{array}$ & $\begin{array}{l}\text { Two cohorts (one for } \\
\text { melanoma and one for } \\
\text { NSCLC), open-label, } \\
\text { nonrandomized }\end{array}$ & $\geq 5 \%$ & Single arm \\
\hline $\begin{array}{l}\text { KEYNOTE-024 } \\
\text { (NCT02 I 42738) }\end{array}$ & III & First line & 305 & $\begin{array}{l}\text { Metastatic with } \\
\text { strong PD-LI } \\
\text { expression }\end{array}$ & $\begin{array}{l}\text { Open-label, } \\
\text { randomized }\end{array}$ & $\geq 50 \%$ & $\begin{array}{l}\text { Pembrolizumab versus six } \\
\text { different platinum doublet } \\
\text { regimens }\end{array}$ \\
\hline $\begin{array}{l}\text { KEYNOTE-042 } \\
\text { (NCT02220894) }\end{array}$ & III & First line & $\mathrm{I}, 240$ & $\begin{array}{l}\text { PD-LI-positive } \\
\text { advanced or } \\
\text { metastatic }\end{array}$ & $\begin{array}{l}\text { Open-label, } \\
\text { randomized }\end{array}$ & $\geq 1 \%$ & $\begin{array}{l}\text { Pembrolizumab versus two } \\
\text { different platinum doublet } \\
\text { regimens }\end{array}$ \\
\hline $\begin{array}{l}\text { KEYNOTE-I89 } \\
(\text { NCT02578680) }\end{array}$ & III & First line & 570 & $\begin{array}{l}\text { Advanced or } \\
\text { metastatic }\end{array}$ & $\begin{array}{l}\text { Double-blind, } \\
\text { randomized }\end{array}$ & Not defined & $\begin{array}{l}\text { Pembrolizumab + platinum } \\
\text { doublet versus platinum } \\
\text { doublet alone }\end{array}$ \\
\hline $\begin{array}{l}\text { KEYNOTE-09I } \\
(\text { NCT02504372) }\end{array}$ & III & $\begin{array}{l}\text { Post adjuvant } \\
\text { therapy }\end{array}$ & $\mathrm{I}, 380$ & Adjuvant & $\begin{array}{l}\text { Double-blind, } \\
\text { randomized }\end{array}$ & Not defined & $\begin{array}{l}\text { Pembrolizumab versus } \\
\text { placebo }\end{array}$ \\
\hline
\end{tabular}

Abbreviations: $\mathrm{AE}$, adverse events; $\mathrm{Cl}$, confidence interval; DFS, disease-free survival; DLT, dose-limiting toxicity; DOR, duration of response; irRECIST, immune-related RECIST; LCSS, lung cancer-specific survival; NA, not available; NSCLC, non-small cell lung cancer; q, every; ORR, objective response rate; OS, overall survival; PD-LI, PD-I ligand I; PFS, progression-free survival; RECIST, Response Evaluation Criteria in Solid Tumors.

ORR was 45.2\% (95\% CI: 33.5-57.3) for those with a PD-L1 proportion score of at least $50 \%(\mathrm{n}=73)$; this included ORR of $43.9 \%$ (95\% CI: 30.7-57.6) in previously treated patients and $50.0 \%$ (95\% CI: 24.7-75.3) in treatment-naïve patients.
While these rates were slightly higher than their corresponding values in the training group, the trend in the pooled analysis, nevertheless, confirmed greater response rate in patients with a higher PD-L1 proportion score. 


\begin{tabular}{|c|c|c|c|c|c|}
\hline \multirow[t]{2}{*}{ Trial status } & \multirow[t]{2}{*}{ Primary endpoints } & \multirow[t]{2}{*}{ Secondary endpoints } & \multicolumn{3}{|l|}{ Results } \\
\hline & & & ORR & PFS & OS \\
\hline Completed & $\begin{array}{l}\text { Number of participants } \\
\text { I) experiencing DLTs, } \\
\text { 2) AE; ORR, change in } \\
\text { biomarker expression }\end{array}$ & $\begin{array}{l}\text { Pharmacokinetics, } \\
\text { pharmacodynamics, PFS, } \\
\text { OS, DOR }\end{array}$ & 19.4\% (95\% Cl: 16.0-22.3) & $\begin{array}{l}3.7 \text { months }(95 \% \mathrm{Cl} \text { : } \\
2.9-4.1)\end{array}$ & $\begin{array}{l}\text { I2.0 months ( } 95 \% \mathrm{Cl} \text { : } \\
9.3-14.7)\end{array}$ \\
\hline Completed & $\begin{array}{l}\text { OS, PFS, number } \\
\text { of participants } \\
\text { I) experiencing AE, } \\
\text { 2) discontinuing study } \\
\text { drug due to AE }\end{array}$ & ORR, DOR & $\begin{array}{l}\mathrm{PD}-\mathrm{LI} \geq 50 \%: 30.2 \% \text { at } \\
\text { pembrolizumab } 2 \mathrm{mg} / \mathrm{kg} \\
\text { versus } 29.1 \% \text { at } 10 \mathrm{mg} / \mathrm{kg} \\
\text { versus } 7.9 \% \text { with docetaxel, } \\
P<0.000 \mathrm{I} \text {; PD-LI } \geq 1 \% \text { : } \\
18.0 \% \text { versus } 18.5 \% \text { versus } \\
9.3 \%, P<0.0005\end{array}$ & $\begin{array}{l}\text { Pembrolizumab } 2 \mathrm{mg} / \mathrm{kg} \\
\text { group: } 3.9 \text { months } \\
\text { (95\% Cl: } 3.1-4.1), \\
\text { pembrolizumab } 10 \mathrm{mg} / \mathrm{kg} \\
\text { group: } 4.0 \text { months } \\
\text { (95\% Cl: } 2.7-4.3) \text {, } \\
\text { docetaxel: } 4.0 \text { months } \\
\text { (95\% Cl: } 3.1-4.2 \text { ) }\end{array}$ & $\begin{array}{l}\text { Pembrolizumab } 2 \mathrm{mg} / \mathrm{kg} \\
\text { group: } 10.4 \text { months } \\
\text { (95\% Cl: } 9.4-11.9), \\
\text { pembrolizumab } 10 \mathrm{mg} / \mathrm{kg} \\
\text { group: } 12.7 \text { months } \\
\text { (95\% Cl: } 10.0-17.3), \\
\text { docetaxel: } 8.5 \text { months } \\
\text { (95\% Cl: } 7.5-9.8)\end{array}$ \\
\hline Ongoing & $\begin{array}{l}\text { Number of participants } \\
\text { experiencing DLTs }\end{array}$ & NA & NA & NA & NA \\
\hline November & ORR (cohorts & PFS, DOR, OS (cohort G) & NA & NA & NA \\
\hline 2016 & $\begin{array}{l}\text { G [carboplatin/ } \\
\text { pemetrexed } \\
\text { with/without } \\
\text { pembrolizumab] } \\
\text { and H [pembrolizumab/ } \\
\text { ipilimumab]), Phase II } \\
\text { dose in combination } \\
\text { with chemotherapy } \\
\text { and immunotherapy (all } \\
\text { cohorts) }\end{array}$ & & & & \\
\hline July 2015 & $\begin{array}{l}\text { ORR (by RECIST } \\
\text { Version I.I), number } \\
\text { of participants } \\
\text { I) experiencing AE, } \\
\text { 2) discontinuing study } \\
\text { treatment due to AE }\end{array}$ & PFS, DOR, OS & Results awaited & NA & NA \\
\hline March 2018 & $\begin{array}{l}\text { ORR (by RECIST } \\
\text { Version I.I) }\end{array}$ & $\begin{array}{l}\text { Brain metastasis response } \\
\text { (by modified RECIST } \\
\text { Version I.I) }\end{array}$ & NA & NA & NA \\
\hline May 2018 & PFS & ORR, OS & NA & NA & NA \\
\hline $\begin{array}{l}\text { February } \\
2018\end{array}$ & OS & PFS & NA & NA & NA \\
\hline September & PFS (by RECIST & ORR (by RECIST Version & NA & NA & NA \\
\hline 2017 & Version I.I) & I.I), OS, PFS (by irRECIST) & & & \\
\hline April 2024 & DFS & OS, LCSS & NA & NA & NA \\
\hline
\end{tabular}

While former/current smokers benefited more with an ORR of $22.5 \%$ (95\% CI: 18.3-27.1) compared to never smokers who had an ORR of 10.3 (95\% CI: 5.6-17.0), this difference between the groups vanished when the data were analyzed under PD-L1 expression subgroups. Similarly, dose or schedule made little difference to the response rates. Median PFS and OS were longer for patients with a PD-L1 expression proportion score of at least $50 \%$ than patients with 
Table 2 Toxicities related to pembrolizumab in NSCLC clinical trials

\begin{tabular}{|c|c|c|c|c|}
\hline Trial & Toxicity & Arm & & \\
\hline KEYNOTE-00 I39,40 & & Pembrolizumab (2 mg/kg or $10 \mathrm{mg} / \mathrm{kg}$ & & \\
\hline \multirow[t]{12}{*}{ (NCT0I 295827) } & & every 3 weeks or $10 \mathrm{mg} / \mathrm{kg}$ every & & \\
\hline & & 2 weeks) & & \\
\hline & Fatigue & $19 \%$ & & \\
\hline & Pruritus & $11 \%$ & & \\
\hline & Decreased appetite & $11 \%$ & & \\
\hline & Rash & $10 \%$ & & \\
\hline & Arthralgia & $9 \%$ & & \\
\hline & Diarrhea & $8 \%$ & & \\
\hline & Nausea & $8 \%$ & & \\
\hline & Hypothyroidism & $7 \%$ & & \\
\hline & Pneumonitis & $4 \%$ & & \\
\hline & Infusion-related reaction & $3 \%$ & & \\
\hline \multirow[t]{12}{*}{$\begin{array}{l}\text { KEYNOTE-0I04I } \\
\text { (NCTOI905657) }\end{array}$} & & $\begin{array}{l}\text { Pembrolizumab ( } 2 \mathrm{mg} / \mathrm{kg} \text { every } \\
3 \text { weeks) }\end{array}$ & $\begin{array}{l}\text { Pembrolizumab ( } 10 \text { mg/kg } \\
\text { every } 3 \text { weeks) }\end{array}$ & $\begin{array}{l}\text { Docetaxel }\left(75 \mathrm{mg} / \mathrm{m}^{2}\right. \\
\text { every } 3 \text { weeks) }\end{array}$ \\
\hline & Any & $63 \%$ & $66 \%$ & $81 \%$ \\
\hline & Decreased appetite & $14 \%$ & $10 \%$ & $16 \%$ \\
\hline & Fatigue & $14 \%$ & $14 \%$ & $25 \%$ \\
\hline & Nausea & $11 \%$ & $9 \%$ & $15 \%$ \\
\hline & Rash & $9 \%$ & $13 \%$ & $5 \%$ \\
\hline & Diarrhea & $7 \%$ & $6 \%$ & $18 \%$ \\
\hline & Asthenia & $6 \%$ & $6 \%$ & $11 \%$ \\
\hline & Hypothyroidism & $8 \%$ & $8 \%$ & $<1 \%$ \\
\hline & Pneumonitis & $5 \%$ & $4 \%$ & $2 \%$ \\
\hline & Hyperthyroidism & $4 \%$ & $6 \%$ & $1 \%$ \\
\hline & Colitis & $1 \%$ & $1 \%$ & $0 \%$ \\
\hline
\end{tabular}

Abbreviation: NSCLC, non-small cell lung cancer.

proportions of $1 \%-49 \%$ or $<1 \%$; at the time of analysis, median OS in patients with proportion score of at least $50 \%$ was not reached.

There was no difference in treatment-related AEs according to dose or schedule. The most common AEs were fatigue (19.4\%), pruritus (10.7\%), and decreased appetite $(10.4 \%)$. Grade 3 or higher AEs were reported in $9.5 \%$ of patients (Table 2). Anemia, of any grade, was seen in $4.2 \%$ of patients. Inflammatory or irAEs included infusion-related reactions $(3 \%)$, hypothyroidism $(6.9 \%)$, and pneumonitis (3.6\%). Grade 3 or higher pneumonitis was noted in nine patients $(1.8 \%)$, of whom one died.

The investigators concluded that pembrolizumab had an acceptable side-effect profile and that it showed similar efficacy with durable responses in patients who received $10 \mathrm{mg} / \mathrm{kg}$ every 2 weeks versus $10 \mathrm{mg} / \mathrm{kg}$ every 3 weeks. Conclusion could not be made about the $2 \mathrm{mg} / \mathrm{kg}$ every 3 weeks regimen because of lack of enough data. They also noted that a PD-L1 proportion score of at least $50 \%$ was associated with a higher ORR and longer PFS and OS than a proportion score $<50 \%$. Hence, they suggested, but were cautious not to establish, a proportion score of at least $50 \%$ as a new biomarker for pembrolizumab-based treatment of NSCLC.

\section{KEYNOTE-0 I 0}

KEYNOTE-010 trial aimed to assess the efficacy of two different doses of pembrolizumab in comparison to docetaxel in previously treated patients with PD-L1-positive advanced NSCLC. ${ }^{41}$

In this manner, it is the first trial that investigated pembrolizumab against an active control in patients enrolled on the basis of their tumor PD-L1 expression proportion. This three-armed, randomized (1:1:1), controlled, Phase II/III trial was performed at 202 medical centers across 24 countries. From August 28, 2013, to February 27, 2015, a total of 1,034 eligible patients, out of a total of 2,699 patients screened, were enrolled on the trial. As in KEYNOTE-001, these patients had ECOG performance status of 0 or 1 and they were 18 years or older in age. Additionally, the patients had to have a tumor PD-L1 proportion score of at least $1 \%$. A vast majority of patients had progressed on two or more cycles of platinum-doublet chemotherapy, as well as an appropriate tyrosine kinase inhibitor (for those with EGFR-sensitizing mutation or ALK rearrangement); in fact, $98 \%$ of patients $(n=1,011)$ had prior chemotherapy with $29 \%$ of patients $(n=300)$ having progressed on two or more lines of therapy. Key exclusion criteria included prior treatment with PD-1 
inhibitors or docetaxel, known active brain metastases or carcinomatous meningitis, interstitial lung disease, and history of pneumonitis or active autoimmune disease requiring systemic steroids. The patients were randomized to receive pembrolizumab intravenously over a 30 -minute period at doses of $2 \mathrm{mg} / \mathrm{kg}$ every 3 weeks ( $\mathrm{n}=345$ ) and $10 \mathrm{mg} / \mathrm{kg}$ every 3 weeks ( $\mathrm{n}=346$ ) or docetaxel $75 \mathrm{mg} / \mathrm{m}^{2}$ intravenously over 1 hour every 3 weeks $(n=343)$. The patients were stratified by ECOG performance status ( 0 vs 1 ), region (East Asia vs not East Asia), and, once established during the midst of the trial, the tumor PD-L1 proportion score $(1 \%-49 \%$ vs $\geq 50 \%)$. Treatment was given for 24 months or until disease progression based on investigator-assessed immune-related response criteria (although RECIST Version 1.1 was used to assess efficacy as in KEYNOTE-001), intolerable toxicity, or patient/investigator decision.

Of all the tumor samples that were assessed $(n=2,222)$, before applying additional eligibility criteria, $66 \%$ had PD-L1 proportion score $\geq 1 \%$, including $28 \%$ who had PD-L1 proportion score $\geq 50 \%$. Eventually, $43 \%$ of the enrolled patients $(n=442)$ had a PD-L1 proportion score of $\geq 50 \%$. The median duration of follow-up was 13.1 months (interquartile range: $8.6-17.7$ ) at the time of data cutoff for analysis (September 30, 2015). For the total population, that is, regardless of the PD-L1 proportion score, the median OS was 10.4 months (95\% CI: 9.4-11.9) for the pembrolizumab $2 \mathrm{mg} / \mathrm{kg}$ arm, 12.7 months (95\% CI: 10.0-17.3) for the pembrolizumab $10 \mathrm{mg} / \mathrm{kg}$ arm, and 8.5 months (95\% CI: 7.5-9.8) for the docetaxel arm. The hazard ratio (HR) for OS for pembrolizumab $2 \mathrm{mg} / \mathrm{kg}$ versus docetaxel was 0.71 (95\% CI: 0.58-0.88) and 0.61 (95\% CI: 0.49-0.75) for pembrolizumab $10 \mathrm{mg} / \mathrm{kg}$ versus docetaxel. These significantly different OS and HR results were even more pronounced for the population with PD-L1 proportion score $\geq 50 \%$. However, there was no difference in OS noted between pembrolizumab $2 \mathrm{mg} / \mathrm{kg}$ and $10 \mathrm{mg} / \mathrm{kg}$ arms in either the total population (HR 1.17; 95\% CI: $0.94-1.45$ ) or that with PD-L1 proportion score $\geq 50 \%$ (HR 1.12; 95\% CI: 0.77-1.62). While the OS benefit on pembrolizumab versus docetaxel favored patients irrespective of their histology, the difference was not statistically significant for those with squamous cell NSCLC (HR 0.74; 95\% CI: 0.50-1.09). Similar to OS, the PFS for the pembrolizumab arms was significantly better than docetaxel for those with PD-L1 proportion score of $\geq 50 \%$ but did not reach statistical difference for the overall population. As it was for the OS, the PFS was similar between the two pembrolizumab doses in the total population (HR 1.09; 95\% CI: $0.92-1.30$ ) and those with PD-L1 proportion score of $\geq 50 \%$ (HR 1.01; $95 \%$
CI: 0.75-1.36). Responses in the pembrolizumab arms were durable; median duration of response was not reached in pembrolizumab arms compared with 6 months (all patients) and 8 months (PD-L1 proportion score $\geq 50 \%$ ).

Grade 3-5 AEs occurred in 13\% $(n=43)$ of patients in the pembrolizumab $2 \mathrm{mg} / \mathrm{kg}$ arm, $16 \%(\mathrm{n}=55)$ of patients in the pembrolizumab $10 \mathrm{mg} / \mathrm{kg}$ arm, and $35 \%(\mathrm{n}=109)$ of patients in the docetaxel arm. Anemia, of any grade, was seen in $3 \%(2 \mathrm{mg} / \mathrm{kg})$ and $4 \%(10 \mathrm{mg} / \mathrm{kg})$ of patients who received pembrolizumab and $14 \%$ of those who received docetaxel. Neutropenia, of any grade, was seen in $<1 \%$ of patients who received pembrolizumab, while it was seen in $14 \%$ of those who received docetaxel. Between the two pembrolizumab arms, $20 \%$ of the patients (133 of 682) had AEs of likely immune etiology irrespective of direct attribution to pembrolizumab. Overall, deaths attributable to pembrolizumab included three cases of pneumonitis, two cases of pneumonia, and one case of myocardial infarction.

The investigators concluded that pembrolizumab was highly efficacious in all patients with PD-L1 expression, although more so in those patients with tumor PD-L1 expression score $\geq 50 \%$ - a finding noted in KEYNOTE-001 as well. Whether this extends to those with PD-L1-negative tumors would need additional investigation. Further, it showed that pembrolizumab at a dose of $2 \mathrm{mg} / \mathrm{kg}$ every 3 weeks was also efficacious. Overall, they concluded pembrolizumab as a new option for treatment of advanced NSCLC in second-line or higher setting for those patients who had PD-L1-positive tumors.

\section{Ongoing trials KEYNOTE-OI I}

In this two-part Phase I trial, the investigators seek to study pembrolizumab in combination with platinum-based chemotherapy. The study assesses the safety and tolerability of pembrolizumab monotherapy (in part A; patients with advanced solid tumors) or in combination with either cisplatin/ pemetrexed or carboplatin/paclitaxel by nonrandom assignment (in part B; patients with Stage IIIB/IV NSCLC).

\section{KEYNOTE-02 I}

This Phase I/II trial with eight cohorts aims to study the safety, tolerability, and efficacy of pembrolizumab in combination with other therapies in treatment-naïve advanced NSCLC. The eight cohorts receive pembrolizumab with conventional cytotoxic chemotherapy such as carboplatin/pemetrexed or carboplatin/paclitaxel (cohorts A, B, C, and G), bevacizumab (cohort B), tyrosine kinase inhibitor - gefitinib or erlotinib 
(cohorts E and F), or anti-CTLA-4 antibody - ipilimumab (cohorts $\mathrm{D}$ and $\mathrm{H}$ ). Preliminary results from cohorts $\mathrm{A}-\mathrm{C}$ (pembrolizumab + chemotherapy) and $\mathrm{D}$ and $\mathrm{H}$ (pembrolizumab + ipilimumab) were reported at the 2015 and 2016 American Society of Clinical Oncology Annual Meetings. ${ }^{42-45}$ In the chemotherapy arms, patients received pembrolizumab $2 \mathrm{mg} / \mathrm{kg}$ or $10 \mathrm{mg} / \mathrm{kg}$ every 3 weeks plus either carboplatin + paclitaxel (cohort A; any histology), carboplatin + paclitaxel + bevacizumab (cohort B, nonsquamous NSCLC), or carboplatin + pemetrexed (cohort C; nonsquamous NSCLC) for four cycles, followed by maintenance pembrolizumab (cohort A), pembrolizumab + bevacizumab (cohort B), or pembrolizumab + pemetrexed (cohort C). ${ }^{44}$ With a median follow-up of 12 months at preliminary data collection point, 74 patients (25 in cohort A, 25 in cohort B, and 24 in cohort C) had been treated. Only one dose-limiting toxicity occurred in cycle 1 in a patient in cohort C. Grade 3-4 treatment-related AEs occurred in 36\%, 46\%, and $42 \%$ of patients in cohorts $\mathrm{A}, \mathrm{B}$, and $\mathrm{C}$, respectively. For patients randomized to receive ipilimumab in addition to pembrolizumab, dose finding was first studied in cohort D. ${ }^{45}$ The dose of pembrolizumab was decreased from $10 \mathrm{mg} / \mathrm{kg}$ to $2 \mathrm{mg}$ / $\mathrm{kg}$ and that of ipilimumab from $3 \mathrm{mg} / \mathrm{kg}$ to $1 \mathrm{mg} / \mathrm{kg}$ based on emerging toxicity data from another study in advanced NSCLC with nivolumab and ipilimumab; these decreased doses were the recommended doses for Phase II dose expansion in cohort $\mathrm{H}$. With a median follow-up of 7 months for 44 patients from cohorts $\mathrm{D}$ and $\mathrm{H}$, treatment-related AEs were noted in $30(67 \%)$ patients of whom 11 (24\%) experienced grade 3-5 treatment-related AEs. Discontinuation of treatment because of treatment-related AEs occurred in four ( $9 \%$ ) patients. One treatment-related death was noted. ORR was $25 \%$, while $40 \%$ had stable disease. Median PFS was 6 months. No obvious association between PD-L1 status and outcomes was reported although long-term follow-up may help better define such associations, if any. ${ }^{45}$ It seems the combination of pembrolizumab and ipilimumab in previously treated advanced NSCLC demonstrated a significant toxicity profile and an ORR similar to that of pembrolizumab alone.

\section{KEYNOTE-025}

This is an open-label, nonrandomized Phase Ib study that aims to evaluate the safety and efficacy of pembrolizumab in PD-L1-positive advanced NSCLC. All participants would receive pembrolizumab $10 \mathrm{mg} / \mathrm{kg}$ intravenously every 3 weeks for up to 2 years. The study is now closed, and results are awaited.

\section{MK-3475 in melanoma and NSCLC patients with brain metastases}

This is an open-label, nonrandomized, Phase II efficacy study of pembrolizumab with two independent arms - patients with metastatic melanoma and NSCLC with untreated brain metastases. Patients with NSCLC must have at least one brain metastasis that is $5-20 \mathrm{~mm}$ in size, asymptomatic, and does not require local therapy at the time of enrollment. PD-L1 tumor proportion score $\geq 5 \%$ from any site is required. The primary outcome is ORR (using RECIST Version $1.1)$, evaluated after 8 weeks of systemic therapy and every 8 weeks thereafter using imaging, while the secondary outcome measure is brain metastasis response (using modified RECIST Version 1.1). Preliminary results were presented at the 16th Annual World Conference on Lung Cancer. ${ }^{46}$ Of the 15 patients with NSCLC and untreated brain metastases who were treated with pembrolizumab, none had a drug-related grade $\geq 3 \mathrm{AE}$. Of the ten patients evaluable for response, five had a brain metastasis response (four partial and one complete) and five had a systemic response. All but one patient who had a systemic response also had a central nervous system response. The duration of response in the brain was at least 12 weeks for four of the five responders.

\section{KEYNOTE-024}

In this international, open-label, randomized, Phase III study, the investigators seek to elucidate the safety and efficacy of pembrolizumab in comparison to standard-of-care platinum-based chemotherapies in the first-line treatment of Stage IV NSCLC. The tumor should have a PD-L1 proportion score $\geq 50 \%$ and not harbor EGFR-sensitizing mutation or ALK rearrangement. Patients are randomized in a 1:1 ratio to pembrolizumab fixed dose $200 \mathrm{mg}$ every 3 weeks for up to 35 cycles or until documented disease progression or investigator's choice of platinum doublet chemotherapy (cisplatin or carboplatin in combination with pemetrexed or gemcitabine or carboplatin/paclitaxel) for four to six cycles. Patients with nonsquamous histology on the platinum doublet arm may choose to continue maintenance with pemetrexed for the remainder of the study or until disease progression. In the latter event, these patients may cross over to receive pembrolizumab. The primary outcome measure is PFS, while the secondary outcome measures include OS and ORR.

\section{KEYNOTE-042}

Similar to KEYNOTE-024, this is in international, open-label, randomized, Phase III trial evaluating the efficacy of pembrolizumab in comparison to platinum doublet chemotherapy 
as frontline treatment of advanced NSCLC. The tumor should not harbor EGFR-sensitizing mutation or ALK rearrangement; however, any PD-L1-positive tumor (ie, proportion score $\geq 1 \%$ ) would be eligible. Patients are randomized in a 1:1 ratio to pembrolizumab fixed dose $200 \mathrm{mg}$ every 3 weeks for up to 35 cycles or until disease progression or investigator's choice of platinum doublet chemotherapy (carboplatin in combination with pemetrexed or paclitaxel) for a maximum of six cycles. Patients with nonsquamous histology on the platinum doublet chemotherapy arm may receive maintenance therapy with pemetrexed. Those on the pembrolizumab arm may stop treatment if they attain complete response and meet criteria for holding therapy. These patients, and those who stop pembrolizumab after receiving the 35 trial doses for reasons other than disease progression or intolerability, may be eligible for retreatment in the case of disease progression. The primary outcome measure is OS, while the secondary outcome measure is PFS by independent radiologist's review.

\section{KEYNOTE-I89}

This is a randomized, double-blinded, Phase III study evaluating the efficacy and safety of platinum doublet (carboplatin or cisplatin with pemetrexed) with or without pembrolizumab $200 \mathrm{mg}$ every 3 weeks in first-line treatment of patients with metastatic nonsquamous NSCLC. Participants should not have an indication for EGFR or ALK rearrangement-directed targeted therapy. Both arms would receive the platinum with pemetrexed chemotherapy for four cycles. After that, the control arm will receive pemetrexed for maintenance, while the experimental arm will receive pemetrexed and pembrolizumab for maintenance. If progression occurs on the control arm, participants may be eligible to receive pembrolizumab for the remainder of the study or until documented progression. The primary and secondary outcome measures are PFS and ORR, respectively, as assessed by blinded central imaging using RECIST Version 1.1. Another secondary outcome measure is PFS as assessed by investigator immunerelated RECIST response criteria.

\section{KEYNOTE-407}

This randomized, double-blinded, Phase III trial aims to compare the outcomes of platinum doublet chemotherapy (carboplatin with paclitaxel or nab-paclitaxel) alone or in combination with pembrolizumab in first-line setting for patients with metastatic squamous NSCLC. Participants will receive either pembrolizumab $200 \mathrm{mg}$ (experimental arm) or saline placebo (control) prior to platinum doublet chemotherapy on day 1 on each 3 -week cycle. The platinum doublet will be given for a maximum of four cycles, while pembrolizumab (experimental arm) and saline placebo (control arm) will continue beyond chemotherapy for up to a total of 35 cycles unless there is documented disease progression, unacceptable AEs, or one of the other predetermined events. For those with verified disease progression, the treatment assignment will be unblinded, and those participants could transition to an optional crossover phase of the study. In the crossover phase, participants who received saline placebo will be able to receive open-label pembrolizumab monotherapy for a total of 35 treatments, while those who had received pembrolizumab, but are deemed to be benefiting clinically, will be able to receive open-label pembrolizumab monotherapy beyond progression to complete a total of 35 treatments. PFS and OS are the primary endpoints, while ORR is the secondary endpoint being measured.

\section{KEYNOTE-09I/PEARLS}

In this randomized, double-blind, Phase III trial, the investigators seek to study the efficacy of pembrolizumab in the adjuvant setting. Participants with Stage IB (tumor $\geq 4 \mathrm{~cm}$ ) or Stage II-IIIa NSCLC (any histology) who have undergone resection (lobectomy/pneumonectomy) and adjuvant therapy for up to a maximum of four cycles will be randomized to receive either placebo or pembrolizumab $200 \mathrm{mg}$ every 3 weeks for 1 year. Disease-free survival is the primary outcome measure, while OS and lung cancer-specific survival are the secondary outcomes measures.

\section{Biomarker use - one issue, many unknowns}

An area of uncertainty is the incorporation of PD-L1 expression in clinical trial development and practice. The rationale behind PD-L1 as a potential biomarker is quite understandable; after all, it is the direct ligand to PD-1 - the target of anti-PD-1 agents such as pembrolizumab and nivolumab. However, the uncertainty arises from the conflicting results and/or inability for comparison secondary to lack of a standardized methodology, variability in PD-L1 antibody assays, lack of a definition of PD-L1 positivity (in terms of proportion score and what cells should be considered - immune cells vs stromal cells vs tumor cells), tissue used for analysis (fresh vs archived sample), the anti-PD-L1 agent used (nivolumab vs pembrolizumab), dynamic nature of PD-L1 expression, and the different malignancies in which it is studied. ${ }^{47-49}$

For NSCLC, CHECKMATE 057 trial showed significant differences in the ORR to nivolumab between PD-L1-positive 
and -negative cohorts (31\% vs 9\%), but CHECKMATE 017 showed no difference in the ORR between the PD-L1-positive and -negative cohorts. ${ }^{50,51}$ That said, it is prudent to mention that CHECKMATE 057 trial enrolled patients with nonsquamous histology, while CHECKMATE 017 trial enrolled those with squamous histology. As discussed earlier, both KEYNOTE-001 and KEYNOTE-010 showed correlation between PD-L1 expression levels ( $\geq 50 \%$ vs less) and outcomes. However, having seen some responses in patients with proportion score $\leq 1 \%$, the investigators of KEYNOTE-001 were upfront in noting that the PD-L1 expression proportion score lacked the characteristics of approved genetically based biomarkers. They also suggested that additional assessment including genomic landscape and presence of preexisting CD8 ${ }^{+} \mathrm{T}$-cells and cytokines in tumor samples may supplement PD-L1 expression in future in successfully identifying the group of patient who may benefit from pembrolizumab.

PD-L1 expression is inducible, highly dynamic, and can be affected by time, stage, and previous treatment. ${ }^{40,47,52}$ As such, the KEYNOTE-001 investigators focused their analysis on contemporaneously collected tissue samples. In contrast, however, the KEYNOTE-010 investigators noted that pembrolizumab provided significant OS benefit compared to docetaxel irrespective of whether new (HR 0.64; 95\% CI: $0.50-0.83$ ) or archived (HR 0.70; 95\% CI: 0.54-0.89) samples were used.

A pooled analysis of six studies with 776 patients showed that patients with PD-L1-positive tumors (PD-L1 tumor cell proportion score $\geq 1 \%$ ) had a significantly higher ORR compared to patients with PD-L1-negative tumors (odds ratio 2.53; 95\% CI: $1.65-3.87) .^{53}$

Whether PD-L1 is a prognostic biomarker is yet another controversy. A recent meta-analysis demonstrated no significant difference in OS in patients with PD-L1-positive versus -negative lung cancer at either 3 years (OR 1.57; 95\% CI: $0.38-6.48$ ) or 5 years (OR 0.91 ; 95\% CI: $0.32-2.63$ ). ${ }^{54}$ On the other hand, another meta-analysis showed worse prognosis with PD-L1 expression in 1,157 NSCLC patients (HR 1.75; 95\% CI: 1.40-2.20). ${ }^{55}$

No significant relationship was seen between PD-L1 expression and clinical features, including sex, histology, smoking status, tumor stage, and lymph node metastases. ${ }^{55}$

It is worth noting that a study in NSCLC patients treated with pembrolizumab showed that high nonsynonymous mutation burden was strongly associated with improved ORR (63\% vs $0 \% ; P=0.03)$, median PFS (14.5 months vs 3.7 months; $P=0.01$ ), and durable clinical benefit $(73 \%$ vs $13 \%){ }^{56}$
The outcomes also correlated with the molecular signature characteristic of tobacco carcinogen-related mutagenesis, certain DNA repair mutations, and the burden of neoantigens with each factor being associated with mutation burden. ${ }^{56}$

It is clear that PD-L1 is not a great prognostic or predictive biomarker. Additionally, we currently lack enough data to truly apply PD-L1 expression levels in routine clinical practice. Any attempts at refining its use as a biomarker would have to start first with standardization of PD-L1 expression assessment. Meanwhile, other biomarkers as just mentioned seem to be emerging. Regardless, as it stands, the FDA approval for nivolumab use does not mandate PD-L1 positivity, but, for pembrolizumab, it requires that the tumors test positive for PD-L1 using a companion assay. Current practice may be biased against pembrolizumab given that PD-L1 testing may delay therapy initiation besides that it lacks excellent positive or negative predictive value in terms of its association with pembrolizumab-related response. However, it is conceivable that the multitude of trials with varying PD-L1 requirements, as shown in Table 1, may potentially refine our understanding of its usage and outcomes correlation. Ultimately, additional knowledge on the correlation of PD-L1 expression and outcomes holds the prospect of cost-effective and personalized medicine delivery.

\section{Discussion}

Immune checkpoint inhibitors have ushered in a new chapter in the treatment of NSCLC. Long and durable responses have been noted in some patients with NSCLC, leading to much hope in providing better outcomes to those who respond. Pembrolizumab has shown impressive ORR and OS benefit in a large basket Phase I trial and a randomized, controlled, Phase II/III clinical trial. Importantly, pembrolizumab has been tolerated well; fewer patients have had any toxicity, or even grade 3 and higher toxicities, on pembrolizumab as compared to docetaxel. Ongoing and future clinical trials will help understand if pembrolizumab could be used as a first-line treatment in NSCLC or in the adjuvant setting. Additional studies will help elucidate its role in the treatment algorithm for those patients with NSCLC who harbor targetable genetic alterations such as EGFR mutations or ALK rearrangement. Whether its combination with anti-CTLA-4 antibody leads to additional benefits is yet to be seen. Nevertheless, oncologists and other clinicians will need to be cognizant at recognizing and managing irAEs. Clinical acumen will also be tested when radiologic progression may actually represent pseudo-progression. Additionally, clinicians currently face the option of selecting between two anti-PD-1 
agents - nivolumab and pembrolizumab - in nearly identical settings. With many other immunotherapeutic agents in the developmental phase, choosing wisely will become ever more important and difficult. The requirement of PD-L1 expression positivity for pembrolizumab may sway clinicians toward using nivolumab. Given that PD-L1 is not the best biomarker, additional studies will be needed to better clarify the usage of PD-L1 expression as a prognostic or predictive marker in those who undergo treatment with pembrolizumab. At the same time, newer biomarkers are being sought to improvise therapeutics and guide clinical practice. That many patients do not show a clinical response to immunotherapies including pembrolizumab or stop responding at a certain point in their course reflects primary and acquired resistance, respectively. ${ }^{57}$ Various reasons including insufficient infiltrating $\mathrm{CD}^{+} \mathrm{T}$-cells, monoclonality of response, loss of neoantigens, lack of sensitivity to interferon signaling, changes in PD-1 expression on infiltrating T-cells, and upregulation of other immune checkpoint receptors have been brought forth as possible mechanisms of acquired resistance to immunotherapies. ${ }^{57}$ Indeed, a study of acquired resistance to pembrolizumab in patients with melanoma identified mutations in the pathways involved in interferon receptor signaling (Janus kinase 1, JAK1, or Janus kinase 2, JAK2) and in antigen presentation ( $\beta$-2-microglobulin $).{ }^{58}$ Loss of $\beta$-2-microglobulin as a mechanism of acquired resistance to several forms of cancer immunotherapy has been shown previously as well. ${ }^{57,58}$ However, much more needs to be done in this area because understanding resistance to immunotherapies will prove crucial.

\section{Acknowledgment}

No financial support was utilized in the preparation of this article.

\section{Disclosure}

The authors report no conflicts of interest in this work.

\section{References}

1. Siegel RL, Miller KD, Jemal A. Cancer statistics, 2015. CA Cancer J Clin. 2015;65(1):5-29.

2. Goldstraw P, Ball D, Jett JR, et al. Non-small-cell lung cancer. Lancet. 2011;378(9804):1727-1740.

3. Pao W, Girard N. New driver mutations in non-small-cell lung cancer. Lancet Oncol. 2011;12(2):175-180.

4. Janku F, Stewart DJ, Kurzrock R. Targeted therapy in non-small-cell lung cancer - is it becoming a reality? Nat Rev Clin Oncol. 2010;7(7): 401-414.

5. Langer CJ. Emerging immunotherapies in the treatment of non-small cell lung cancer (NSCLC): the role of immune checkpoint inhibitors. Am J Clin Oncol. 2015;38(4):422-430.
6. Masters GA, Temin S, Azzoli CG, et al. Systemic therapy for stage IV non-small-cell lung cancer: American society of clinical oncology clinical practice guideline update. J Clin Oncol. 2015;33(30):3488-3515.

7. Ettinger DS, Wood DE, Akerley W, et al. Non-Small cell lung cancer, version 6.2015. J Natl Compr Cancer Netw. 2015;13(5):515-524.

8. Shaw AT, Ou SI, Bang Y, et al. Crizotinib in ROS1-rearranged nonsmall-cell lung cancer. $N$ Engl J Med. 2014;371(21):1963-1971.

9. Fukuoka M, Wu YL, Thongprasert S, et al. Biomarker analyses and final overall survival results from a phase III, randomized, open-label, first-line study of gefitinib versus carboplatin/paclitaxel in clinically selected patients with advanced non-small-cell lung cancer in Asia (IPASS). J Clin Oncol. 2011;29(21):2866-2874.

10. Zhou C, Wu YL, Chen G, et al. Final overall survival results from a randomised, phase III study of erlotinib versus chemotherapy as first-line treatment of EGFR mutation-positive advanced non-small-cell lung cancer (OPTIMAL, CTONG-0802). Ann Oncol. 2015;26(9):1877-1883.

11. Yang JC, Wu YL, Schuler M, et al. Afatinib versus cisplatin-based chemotherapy for EGFR mutation-positive lung adenocarcinoma (LUX-lung 3 and LUX-lung 6): analysis of overall survival data from two randomised, phase 3 trials. Lancet Oncol. 2015;16(2):141-151.

12. Sandler A, Gray R, Perry MC, et al. Paclitaxel-carboplatin alone or with bevacizumab for non-small-cell lung cancer. N Engl J Med. 2006; 355(24):2542-2550.

13. Kwak EL, Bang YJ, Camidge DR, et al. Anaplastic lymphoma kinase inhibition in non-small-cell lung cancer. $N$ Engl J Med. 2010;363(18): 1693-1703.

14. Paez JG, Janne PA, Lee JC, et al. EGFR mutations in lung cancer: correlation with clinical response to gefitinib therapy. Science. 2004; 304(5676): 1497-1500.

15. Katayama R, Shaw AT, Khan TM, et al. Mechanisms of acquired crizotinib resistance in ALK-rearranged lung cancers. Sci Transl Med. 2012;4(120):ra17-ra120.

16. Kobayashi S, Boggon TJ, Dayaram T, et al. EGFR mutation and resistance of non-small-cell lung cancer to gefitinib. N Engl J Med. 2005; 352(8):786-792.

17. Politi K, Ayeni D, Lynch T. The next wave of EGFR tyrosine kinase inhibitors enter the clinic. Cancer Cell. 2015;27(6):751-753.

18. Al-Moundhri M, O’Brien M, Souberbielle BE. Immunotherapy in lung cancer. Br J Cancer. 1998;78(3):282-288.

19. Kradin RL, Kurnick JT, Lazarus DS, et al. Tumour-infiltrating lymphocytes and interleukin-2 in treatment of advanced cancer. Lancet. 1989;1(8638):577-580.

20. Margolin KA, Rayner AA, Hawkins MJ, et al. Interleukin-2 and lymphokine-activated killer cell therapy of solid tumors: analysis of toxicity and management guidelines. J Clin Oncol. 1989;7(4):486-498.

21. Yano T, Sugio K, Yamazaki K, et al. Postoperative adjuvant adoptive immunotherapy with lymph node-LAK cells and IL-2 for pathologic stage I non-small cell lung cancer. Lung Cancer. 1999;26(3): 143-148.

22. Pardoll DM. The blockade of immune checkpoints in cancer immunotherapy. Nat Rev Cancer. 2012;12(4):252-264.

23. Topalian SL, Drake CG, Pardoll DM. Immune checkpoint blockade: a common denominator approach to cancer therapy. Cancer Cell. 2015; 27(4):450-461.

24. Allison JP. Immune checkpoint blockade in cancer therapy: the 2015 Lasker-DeBakey clinical medical research award. JAMA. 2015; 314(11):1113-1114.

25. Ishida Y, Agata Y, Shibahara K, Honjo T. Induced expression of PD-1, a novel member of the immunoglobulin gene superfamily, upon programmed cell death. EMBO J. 1992;11(11):3887-3895.

26. Riley JL. PD-1 signaling in primary T cells. Immunol Rev. 2009;229(1): 114-125.

27. Anagnostou VK, Brahmer JR. Cancer immunotherapy: a future paradigm shift in the treatment of non-small cell lung cancer. Clin Cancer Res. 2015;21(5):976-984.

28. Keir ME, Butte MJ, Freeman GJ, Sharpe AH. PD-1 and its ligands in tolerance and immunity. Annu Rev Immunol. 2008;26:677-704. 
29. Dong H, Strome SE, Salomao DR, et al. Tumor-associated B7-H1 promotes T-cell apoptosis: a potential mechanism of immune evasion. Nat Med. 2002;8(8):793-800.

30. Zou W, Chen L. Inhibitory B7-family molecules in the tumour microenvironment. Nat Rev Immunol. 2008;8(6):467-477.

31. Dong H, Zhu G, Tamada K, Chen L. B7-H1, a third member of the B7 family, co-stimulates T-cell proliferation and interleukin-10 secretion. Nat Med. 1999;5(12):1365-1369.

32. Latchman Y, Wood CR, Chernova T, et al. PD-L2 is a second ligand for PD-1 and inhibits T cell activation. Nat Immunol. 2001;2(3):261-268.

33. Barber DL, Wherry EJ, Masopust D, et al. Restoring function in exhausted CD8 T cells during chronic viral infection. Nature. 2006; 439(7077):682-687.

34. Fife BT, Pauken KE, Eagar TN, et al. Interactions between PD-1 and PD-L1 promote tolerance by blocking the TCR-induced stop signal. Nat Immunol. 2009;10(11):1185-1192.

35. Hamid O, Robert C, Daud A, et al. Safety and tumor responses with lambrolizumab (anti-PD-1) in melanoma. $N$ Engl J Med. 2013; 369(2):134-144.

36. Merck \& Co. KEYTRUDA (Pembrolizumab) Prescribing Information. 2016. http://www.merck.com/product/usa/pi_circulars/k/keytruda/ keytruda_pi.pdf. Accessed 12 August 2016.

37. Khoja L, Butler MO, Kang SP, Ebbinghaus S, Joshua AM. Pembrolizumab. J Immunother Cancer. 2015;3:36.

38. Gangadhar TC, Salama AK. Clinical applications of PD-1-based therapy: a focus on pembrolizumab (MK-3475) in the management of melanoma and other tumor types. Onco Targets Ther. 2015;8: 929-937.

39. Patnaik A, Kang SP, Rasco D, et al. Phase I study of pembrolizumab (MK-3475; anti-PD-1 monoclonal antibody) in patients with advanced solid tumors. Clin Cancer Res. 2015;21(19):4286-4293.

40. Garon EB, Rizvi NA, Hui R, et al. Pembrolizumab for the treatment of non-small-cell lung cancer. N Engl J Med. 2015;372(21):2018-2028.

41. Herbst RS, Baas P, Kim DW, et al. Pembrolizumab versus docetaxel for previously treated, PD-L1-positive, advanced non-small-cell lung cancer (KEYNOTE-010): a randomised controlled trial. Lancet. 2016;387(10027):1540-1550.

42. Papadimitrakopoulou V, Patnaik A, Borghaei H, et al. Pembrolizumab (pembro; MK-3475) plus platinum doublet chemotherapy (PDC) as front-line therapy for advanced non-small cell lung cancer (NSCLC): KEYNOTE-021 cohorts A and C. J Clin Oncol. 2015; 33(15_suppl):8031.

43. Patnaik A, Socinski MA, Gubens MA, et al. Phase 1 study of pembrolizumab (pembro; MK-3475) plus ipilimumab (IPI) as second-line therapy for advanced non-small cell lung cancer (NSCLC): KEYNOTE-021 cohort D. J Clin Oncol. 2015;33(15_suppl):8011.
44. Gadgeel SM, Stevenson J, Langer CJ, et al. Pembrolizumab (pembro) plus chemotherapy as front-line therapy for advanced NSCLC: KEYNOTE-021 cohorts A-C. J Clin Oncol. 2016;34(15_suppl):9016.

45. Gubens MA, Sequist LV, Stevenson J, et al. Phase I/II study of pembrolizumab (pembro) plus ipilimumab (ipi) as second-line therapy for NSCLC: KEYNOTE-021 cohorts D and H. J Clin Oncol. 2016;34(15_suppl):9027.

46. Goldberg S, Gettinger S, Mahajan A, et al. A phase II trial of pembrolizumab for untreated brain metastases from non-small cell lung cancer. Presented at: 16th Annual World Conference on Lung Cancer, 6-9 September 2015. Denver, CO: 2015.

47. Fusi A, Festino L, Botti G, et al. PD-L1 expression as a potential predictive biomarker. Lancet Oncol. 2015;16(13):1285-1287.

48. Meng X, Huang Z, Teng F, Xing L, Yu J. Predictive biomarkers in PD-1/PD-L1 checkpoint blockade immunotherapy. Cancer Treat Rev. 2015;41(10):868-876.

49. Remon J, Chaput N, Planchard D. Predictive biomarkers for programmed death-1/programmed death ligand immune checkpoint inhibitors in nonsmall cell lung cancer. Curr Opin Oncol. 2016;28(2):122-129.

50. Brahmer J, Reckamp KL, Baas P, et al. Nivolumab versus docetaxel in advanced squamous-cell non-small-cell lung cancer. $N$ Engl J Med. 2015;373(2):123-135.

51. Borghaei H, Paz-Ares L, Horn L, et al. Nivolumab versus docetaxel in advanced nonsquamous non-small-cell lung cancer. $N$ Engl J Med. 2015;373(17):1627-1639.

52. Omori S, Kenmotsu H, Abe M, et al. Changes in PD-L1 expression in non-small cell lung cancer by immunohistochemical analysis. J Clin Oncol. 2015;33(15_suppl):e22118.

53. Sortino G. PD-L1 expression as predictive biomarker in patients with NSCLC: a pooled analysis. Presented at: 16th Annual World Conference on Lung Cancer, 6-9 September 2015. Denver, CO: 2015.

54. Wu P, Wu D, Li L, Chai Y, Huang J. PD-L1 and survival in solid tumors: a meta-analysis. PLoS One. 2015;10(6):e0131403.

55. Wang A, Wang HY, Liu Y, et al. The prognostic value of PD-L1 expression for non-small cell lung cancer patients: a meta-analysis. Eur J Surg Oncol. 2015;41(4):450-456.

56. Rizvi NA, Hellmann MD, Snyder A, et al. Cancer immunology. mutational landscape determines sensitivity to PD-1 blockade in non-small cell lung cancer. Science. 2015;348(6230):124-128.

57. Restifo NP, Smyth MJ, Snyder A. Acquired resistance to immunotherapy and future challenges. Nat Rev Cancer. 2016;16(2):121-126.

58. Zaretsky JM, Garcia-Diaz A, Shin DS, et al. Mutations associated with acquired resistance to PD-1 blockade in melanoma. N Engl J Med. 2016; 375(9):819-829.
OncoTargets and Therapy

\section{Publish your work in this journal}

OncoTargets and Therapy is an international, peer-reviewed, open access journal focusing on the pathological basis of all cancers, potential targets for therapy and treatment protocols employed to improve the management of cancer patients. The journal also focuses on the impact of management programs and new therapeutic agents and protocols on
Dovepress

patient perspectives such as quality of life, adherence and satisfaction. The manuscript management system is completely online and includes a very quick and fair peer-review system, which is all easy to use. Visit http://www.dovepress.com/testimonials.php to read real quotes from published authors. 